\title{
Association of Adjuvants with Culture Filtrate from Fusarium fujikuroi for Increasing the Control of Conyza $s p$.
}

\author{
Jair João Daniel Jr. ${ }^{1}$, Thiarles Brun 1(D), Izelmar Todero ${ }^{1}{ }^{(\mathbb{D}}$, Thiago Almeida ${ }^{1}$, Tássia Confortin ${ }^{1,2}(\mathbb{D}$,

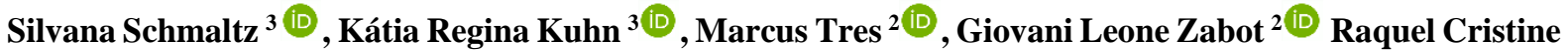 \\ Kuhn ${ }^{3}$ (i) , Marcio Antonio Mazutti ${ }^{3, *}$ (D) \\ 1 Department of Agricultural Engineering, Federal University of Santa Maria, 1000, Roraima avenue, Santa Maria, RS, \\ 97105-900, Brazil \\ 2 Laboratory of Agroindustrial Processes Engineering (LAPE), Federal University of Santa Maria, 1345, Ernesto Barros \\ Street, Cachoeira do Sul, RS, 96506-322, Brazil; $\quad{ }^{3}$ Department of Chemical Engineering, Federal University of Santa \\ Maria, 1000, Roraima avenue, Santa Maria, RS, 97105-900, Brazil \\ * Correspondence: mazutti@ufsm.br;
}

Scopus Author ID 6505485502

Received: 25.04.2020; Revised: 7.05.2020; Accepted: 9.05.2020; Published: 13.05.2020

\begin{abstract}
Metabolites from Fusarium fujikuroi were used as a bioherbicide product for the control of Conyza sp., a weed that causes considerable losses in the cultivation of soybean worldwide. Formulations containing distilled water or culture filtrate and different adjuvants (palm, soybean or mineral oil, Span ${ }^{\circledR} 80$ and Tween ${ }^{\circledR} 80$ ) were evaluated in order to increase the bioherbicidal activity through post-emergence bioassays. The herbicidal activity of culture filtrate was improved using different combinations of adjuvants. The best formulation was 3\% (w/v) of mineral oil, $5.5 \%(\mathrm{w} / \mathrm{v})$ of surfactant (Span ${ }^{\circledR} 80$ and Tween ${ }^{\circledR} 80$ ) and a hydrophilic-lipophilic balance (HLB) of 15, which resulted in a higher herbicidal activity (100\%) (complete death of plants) and lower phytotoxicity (0\%). The suitable combination of adjuvants in association with culture filtrate from F. fujikuroi increased up to 2.5 times the efficiency of bioherbicide for the post-emergence control of Conyza $s p$.
\end{abstract}

Keywords: bioherbicide; biotechnology process; submerged fermentation; formulation; weed control.

(C) 2020 by the authors. This article is an open access article distributed under the terms and conditions of the Creative Commons Attribution (CC BY) license (https://creativecommons.org/licenses/by/4.0/).

\section{Introduction}

Weed control in agricultural areas has been one of the major challenges facing agriculture around the world for many decades. In Brazil, the Conyza sp., popularly known as "buva", has gained prominence in the soybean crop, mainly due to the presence of plants with highly competitive and dispersive potential, which could cause irreversible damage to the crop [1]. The control of Conyza sp. is usually accomplished through the use of chemical herbicides such as glyphosate. However, over the years, some species, including Conyza sp., become resistant to the mechanism of action of certain chemicals [2]. Such synthetic products, like glyphosate, effectively assist the farmer in achieving high productivity in short-term. However, in the long-term, they have negative results for the society and environment, thus requiring studies for using natural bioproducts [3-8].

Taking into account this scenario, the prospection and discovery of new molecules appear as an important tool for the control of resistant weeds [9]. Some studies have shown promising results in the weed control using fermented broth containing the secondary 
metabolites produced by fungi via submerged fermentation [10-14]. Secondary metabolites can damage weeds by penetrating the plant followed by the destruction of the cell wall and induction of necrotic lesions $[15,16]$.

On the other hand, many promising biomolecules are early discarded during the stages of bioherbicide development because they present low herbicidal activity. In a general way, low efficiency is a consequence of the very low concentration of biomolecules in the fermentation media [17]. Therefore, some strategies to concentrate these molecules are essential to obtain an efficient product. In the meanwhile, it is necessary to use an adequate combination of adjuvants in the formulation to increase the herbicidal activity. Adjuvants are substances present in a formulation with the aim of modifying the biological activity or the application characteristics of the formulation $[18,19,20]$. This is highlighted in a study reported by Bastos et al. [21], in which the authors increased three times the herbicidal activity of culture filtrate from Diaphorte sp. obtained by solid state fermentation using $5.5 \mathrm{wt} \%$ of palm oil, 5.5 wt\% of adjuvants and HLB 15.0.

The genus Fusarium has been widely used in the production of metabolites for weed control [22]. The herbicidal activity of different species (Fusarium avenaceum, Fusarium acuminatum, Fusarium redolens, Fusarium culmorum/Fusarium cerealis and Fusarium solani) was evalauted in different grass species, demonstrating promising results using Fusarium avenaceum and Fusarium acuminatum [23]. Recently, our research group isolated and identified the fungus Fusarium fujikuroi obtained from the Brazilian Pampa biome with herbicidal activity towards target plants, such as Cucumis sativus and Sorghum bicolor [24]. However, the potential of this strain for controlling resistant plants as Conyza sp. has not been investigated up to now. Based on these aspects, the objective of this study was to evaluate the efficiency of using adjuvants in association with fermented broth produced by the fungus Fusarium fujikuroi, isolated from the Pampa biome, for the control of Conyza sp., a resistant weed in soybean crop.

\section{Materials and Methods}

\subsection{Materials.}

Corn steep liquor (CSL) was purchased from Ingredion (Mogi Guaçu, SP, Brazil). Palm oil (Elaeis guineensis) was provided by Agropalma (Tailândia, PA, Brazil). Soybean oil and sucrose (cristal) were purchased in a local market (Santa Maria, Brazil) and mineral oil Assist ${ }^{\circledR}$ was purchased from BASF S.A. (São Paulo, SP, Brazil). Silwet L-77 (FMC) and commercial substrate (Mecplant ${ }^{\circledR}$ ) were purchased in a local agricultural supply store (Santa Maria, Brazil). Potato dextrose agar (PDA), (NH4)2SO4, FeSO4.7H2O, MnSO4.H2O, MgSO4, Tween® 80 and Span® 80 were purchased from Sigma-Aldrich (São Paulo, SP, Brazil).

\subsection{Fermentation.}

Fusarium fujikuroi was previously isolated by Daniel et al [24]. The culture was maintained in a petri dish with PDA medium between $4{ }^{\circ} \mathrm{C}$ and $6{ }^{\circ} \mathrm{C}$ and subcultured every 15 days. For pre-inoculum cell production was done incubating the culture on PDA in a Petri dish for 8 days at $28^{\circ} \mathrm{C}$. Afterward, three discs of $6 \mathrm{~mm}$ of fungal mycelium were transferred to the fermentation flasks. The fermentation was carried out in Erlenmeyer flasks containing $125 \mathrm{~mL}$ of fermentation medium under stirring in an Orbital Incubator Shaker (Innova 44R, New Brunswick, Canada) at $31{ }^{\circ} \mathrm{C}$ and $200 \mathrm{rpm}$ for 7 days. The medium was composed of $(\mathrm{g} / \mathrm{L})$ : 
sucrose (10.0), corn steep liquor (50.0), (NH4)2SO4 (0.5), FeSO4.7H2O (1.0), MnSO4.H2O (1.0) and $\mathrm{MgSO} 4$ (0.5). The initial $\mathrm{pH}$ was adjusted to 6.0 [11]. After the fermentation, the cells were separated from the medium by centrifugation at $4000 \mathrm{rpm}$ for $10 \mathrm{~min}$ (Eppendorf, model 5804R, Germany) and the supernatant was filtered using a $0.45 \mu \mathrm{m}$ Polyvinylidene Difluoride (PVDF) membrane. The filtered samples (culture filtrate) were used to formulate the bioherbicide applied in the control of Conyza sp.

\subsection{Formulation of bioherbicide.}

Initially, three different oils (palm, soybean and mineral oil) in association with distilled water or culture filtrate were tested (Table 1). The objective of using oil in the formulation was to increase the adhesion and permanence of the fermented in the foliar area of the plants [25]. After the choice of mineral oil as the best oil, a central composite rotatable design (CCRD) with three independent variables (oil concentration, surfactant concentration and hydrophiliclipophilic balance (HLB)) was evaluated. One assay with only culture filtrate and a control assay with distilled water were also carried out. Table 2 presents the range investigated for each variable. Two surfactants with different hydrophilic-lipophilic balance (HLB) were used: Tween ${ }^{\circledR} 80(\mathrm{HLB}=15.0)$ and Span ${ }^{\circledR} 80(\mathrm{HLB}=4.3)$.

The formulations were prepared at $25^{\circ} \mathrm{C}$ using a Turrax homogenizer model MA102 (Marconi, Piracicaba, SP, Brazil). Firstly, oil (oil and Span® 80) and aqueous (distilled water or culture filtrate and Tween ${ }^{\circledR} 80$ ) phases were homogenized separately for $1 \mathrm{~min}$ at $7000 \mathrm{rpm}$. Then, the oil phase was slowly added to the aqueous phase and the mixture was homogenized in Turrax for at $7000 \mathrm{rpm}$ for $10 \mathrm{~min}$. The final emulsion volume was $50 \mathrm{~mL}$. The samples were maintained at rest for $1 \mathrm{~h}$ before their use in the bioassays.

\subsection{Bioassays.}

The formulation efficiency in the control of Conyza sp. was evaluated through postemergence bioassays with young plants. The plants were collected in the agricultural area of Federal University of Santa Maria (UFSM, Santa Maria, Brazil) and transplanted into polyethylene cups containing $200 \mathrm{~g}$ of the commercial substrate (Mecplant ${ }^{\circledR}$ ) without treatment. They were cultivated in a greenhouse for 15 days before the application of bioherbicide, which was applied using a backpack sprayer, pressurized by $\mathrm{CO}$, provided by a bar pattern with four tips, model Teejet XR 110.02, with a spacing tips of $0.5 \mathrm{~m}$ and pressure of $276 \mathrm{kPa}$. The travel velocity was $1 \mathrm{~m} / \mathrm{s}$ and the specific volume of liquid was $200 \mathrm{~L} / \mathrm{ha}$. Phytotoxicity assays were also performed with the respective formulations, however replacing the culture filtrate by distilled water. The plant injury was visually estimated 15 days after bioherbicide application, following the methodology proposed by Frans and Crowley [26].

\subsection{Tukey's test.}

Statistical differences between the treatments were determined by Tukey's test ( $\mathrm{p}$-value $<0.05)$.

Table 1. Herbicidal activity of formulations with different oils.

\begin{tabular}{ccc}
\hline Treatment & Formulation $(\mathbf{m L})$ & Herbicidal activity (\%) \\
\hline T1 & Culture filtrate $(47.5)+$ palm oil $(2.5)$ & $10^{\mathrm{A}}$ \\
\hline T2 & Culture filtrate $(47.5)+$ soybean oil $(2.5)$ & $10^{\mathrm{A}}$ \\
\hline T3 & Culture filtrate $(47.5)+$ mineral oil $(2.5)$ & $80^{\mathrm{B}}$ \\
\hline T4 & Distilled water $(47.5)+$ palm oil $(2.5)$ & $5^{\mathrm{A}}$ \\
\hline T5 & Distilled water $(47.5)+$ soybean oil $(2.5)$ & $5^{\mathrm{A}}$ \\
\hline
\end{tabular}




\begin{tabular}{ccc}
\hline Treatment & Formulation $(\mathbf{m L})$ & Herbicidal activity (\%) \\
\hline T6 & Distilled water (47.5) + mineral oil (2.5) & $10^{\mathrm{A}}$ \\
\hline T7 & Culture filtrate (50) & $5^{\mathrm{A}}$ \\
\hline T8 & Distilled water (50) & $0^{\mathrm{A}}$ \\
\hline
\end{tabular}

* Means followed by the same letter in the column didn't differ statistically by the Tukey's test at $95 \%$ of confidence level $(\mathrm{p}-\mathrm{value}<0.05)$

Table 2. Influence of different combinations of adjuvants on the herbicidal activity and the phytotoxicity of the formulations.

\begin{tabular}{|c|c|c|c|c|c|}
\hline Treatment & $\begin{array}{c}\text { Oil } \\
(\%, \mathbf{m} / \mathbf{v})\end{array}$ & $\begin{array}{c}\text { Surfactant (\%, } \\
\mathrm{m} / \mathrm{v})\end{array}$ & HLB & $\begin{array}{c}\text { Herbicidal activity } \\
(\%)^{1}\end{array}$ & $\begin{array}{c}\begin{array}{c}\text { Phytotoxicity } \\
(\%)^{2}\end{array} \\
\end{array}$ \\
\hline T1 & $1.81(-1)$ & $2.8(-1)$ & $6.5(-1)$ & $20^{\mathrm{B}}$ & 10 \\
\hline T2 & $4.19(1)$ & $2.8(-1)$ & $6.5(-1)$ & $80^{\mathrm{DE}}$ & 10 \\
\hline T3 & $1.81(-1)$ & $8.2(1)$ & $6.5(-1)$ & $80^{\mathrm{DE}}$ & 15 \\
\hline $\mathbf{T 4}$ & $4.19(1)$ & $8.2(1)$ & $6.5(-1)$ & $40^{\mathrm{BC}}$ & 10 \\
\hline T5 & $1.81(-1)$ & $2.8(-1)$ & $12.8(1)$ & $50^{\mathrm{BC}}$ & 15 \\
\hline T6 & $4.19(1)$ & $2.8(-1)$ & $12.8(1)$ & $30^{\mathrm{B}}$ & 10 \\
\hline T7 & $1.81(-1)$ & $8.2(1)$ & $12.8(1)$ & $80^{\mathrm{DE}}$ & 10 \\
\hline T8 & $4.19(1)$ & $8.2(1)$ & $12.8(1)$ & $90^{\mathrm{E}}$ & 10 \\
\hline T9 & $1(-1.68)$ & $5.5(0)$ & $9.7(0)$ & $70^{\mathrm{DE}}$ & 10 \\
\hline T10 & $5(1.68)$ & $5.5(0)$ & $9.7(0)$ & $100^{\mathrm{F}}$ & 20 \\
\hline T11 & $3(0)$ & $1(-1.68)$ & $9.7(0)$ & $40^{\mathrm{BC}}$ & 10 \\
\hline T12 & $3(0)$ & $10(1.68)$ & $9.7(0)$ & $100^{\mathrm{F}}$ & 10 \\
\hline T13 & $3(0)$ & $5.5(0)$ & $\begin{array}{l}4.3(- \\
1.68)\end{array}$ & $20^{\mathrm{B}}$ & 10 \\
\hline T14 & $3(0)$ & $5.5(0)$ & $15(1.68)$ & $100^{\mathrm{F}}$ & $\mathbf{0}$ \\
\hline T15 & $3(0)$ & $5.5(0)$ & $9.7(0)$ & $100^{\mathrm{F}}$ & 10 \\
\hline T16 & $3(0)$ & $5.5(0)$ & $9.7(0)$ & $100^{\mathrm{F}}$ & 10 \\
\hline T17 & $3(0)$ & $5.5(0)$ & $9.7(0)$ & $70^{\mathrm{DE}}$ & 10 \\
\hline Culture filtrate & 0.0 & 0.0 & 0.0 & $40^{\mathrm{BC}}$ & 0 \\
\hline $\begin{array}{c}\text { Control } \\
\text { (distilled } \\
\text { water) }\end{array}$ & 0.0 & 0.0 & 0.0 & $0^{\mathrm{A}}$ & 0 \\
\hline
\end{tabular}

* Means followed by the same letter in the column didn't differ statistically by the Tukey's test at $95 \%$ of confidence level (p-value $<0.05)$.

2Distilled water + adjuvants

1Culture filtrate + adjuvants

\section{Results and Discussion}

The influence of oil used in the formulations is presented in Table 1. Treatments T1 and T2 formulated with palm and soybean oil, respectively, had a slight effect on the aerial part of Conyza sp. plants, whereas the treatment T3, formulated with mineral oil, showed a severe effect. The control treatments T4 and T5 did not present a phytotoxic effect, while the control treatment T6 showed a slight effect on plants. The treatment T7, composed of culture filtrate, had a low effect on plants, with only a slight yellowing at the leaf ends. Among the oils tested in the study, mineral oil presented the best results. Therefore, it was selected for the next steps of processing and analyses.

Table 2 presents the results obtained in the 17 formulations of the CCRD, in the formulation with only culture filtrate and in the control assay with distilled water, and the differences between the treatments, determined by Tukey's test $(\mathrm{p}<0.05)$. Treatments T1, T6 and T13 presented slight injury. Moderate herbicidal activity was observed in the treatments T4, T5 and T11. For the treatments, T2, T3, T7 - T9 and T17, a severe injury on plants was reported. In the treatments T10, T12 and T14 - T16, the death of plants was verified. The phytotoxicity results showed a slight wilting at the leaf end in some cases. This behavior could be indicating that the herbicidal activity found in the treatments is associated with the presence of biomolecules produced by $F$. fujikuroi and not to the adjuvants used in the formulations. Comparing the results obtained in the 17 formulations with that one of culture filtrate, it was 
possible to observe the intensification of symptoms with the addition of the adjuvants in most treatments. Applying only distilled water to the plants, no symptoms were verified. Figure 1 presents the visual aspects (qualitative description) of Conyza sp. plants for all treatments.

The obtained results suggest that the bioherbicide produced by $F$. fujikuroi could be a hydrophilic molecule because surfactants with a high HLB increase the cuticle hydration. Consequently, it promotes a better permeability of hydrophilic herbicides into the leaves, increasing their diffusion rate at a constant concentration gradient [27]. This is corroborated by the lower result of herbicidal activity obtained in the treatment T13, which was related to the lowest HLB evaluated (Table 2 and Figure 1). The results obtained were similar to those obtained by Bastos et al. [21], whose authors verified that the efficiency of formulated bioherbicide from Diaporthe sp. was higher with HLB 15.0.

The formulation is an important step in the development of a bioherbicide with metabolites from fungi. Without an adequate combination of adjuvants, many bioproducts with great attractiveness in the market are discharged. In this work, the efficiency of the bioherbicide was improved approximately 2.5 times when compared with non-formulated products. Bastos et al. [21] increased 3 times the efficiency of a bioherbicide produced from Diaphorte sp. Likewise, Pes et al. [28] accentuated the suppressive effect on the growth of Conyza sp. and Echinochloa sp. for a bioherbicide formulated from Diaphorte sp. Aybeke [29] reported toxic effects of Fusarium oxysporum on a root parasitic weed (Orobanche spp.). Li et al. [30] reported that ethyl acetate extract of the fermentation broth of Fusarium proliferatum provided selective phytotoxic activity against the radicle growth of Amaranthus retroflexus. Nevertheless, there are no reports about metabolites from Fusarium fujikuroi in the control of Conyza sp. up to now. Therefore, this work can be considered the first study related to the herbicidal activity of metabolites from Fusarium fujikuroi isolated from a local area (Santa Maria, Brazil) in the Pampa biome for the control of this weed.

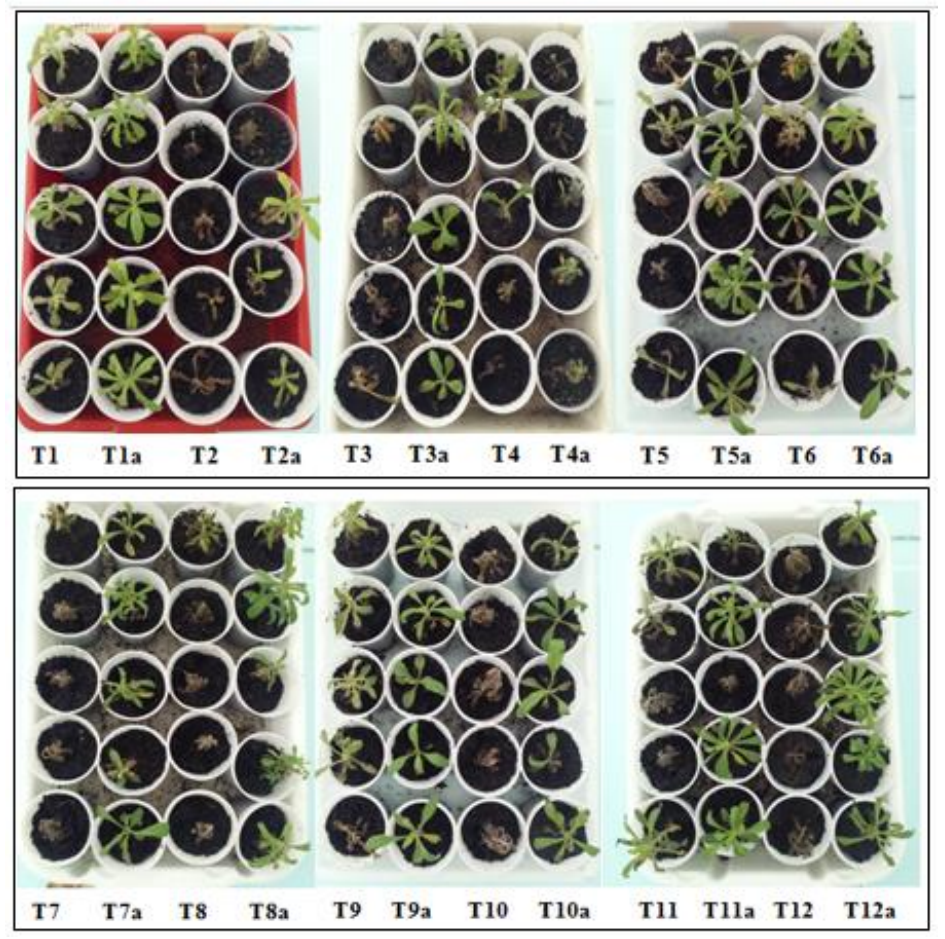

Figure 1. Visual aspect of Conyza sp. plants after the application of different formulations: herbicidal activity (culture filtrate + adjuvants: T1 - T17), phytotoxicity (distilled water + adjuvants: T1a - T17a), culture filtrate (F) and distilled water (control test). 


\section{Conclusions}

In this study, the necessity of a correct combination of adjuvants to increase the herbicide activity of culture filtrate was demonstrated. Depending on the adjuvants combination, the herbicidal activity may reach values insufficient to follow the next steps in the development stage. The better result of herbicidal activity was obtained with a formulation containing $3 \%(\mathrm{w} / \mathrm{v})$ of mineral oil, $5.5 \%(\mathrm{w} / \mathrm{v})$ of surfactant and HLB of 15 , a condition in which a complete death of Conyza sp. plants was observed. This promising combination of adjuvants and culture filtrate from $F$. fujikuroi increased 2.5 times the efficiency of bioherbicide for the post-emergence control of Conyza sp.

\section{Funding}

This research received no external funding.

\section{Acknowledgments}

The authors thank the Coordination for the Improvement of Higher Education Personnel (CAPES) for the scholarships, and the National Council of Technological and Scientific Development (CNPq), the Secretary of Economic Development, Science and Technology of the State of Rio Grande do Sul (SDECT-RS) and the Research Support Foundation of the State of Rio Grande do Sul (FAPERGS) for the financial support.

\section{Conflicts of Interest}

The authors declare no conflict of interest.

\section{References}

1. Vieira, E.; Guerra, N.; Mendes de Oliveira Neto, A. Efeito da adição de adjuvantes a mistura em tanque de glyphosate + chlorimuron ethyl no controle de buva. Campo Digit@l 2015, 10, 71-78.

2. Green, J.M. Current state of herbicides in herbicide-resistant crops. Pest Management Science 2014, 70, 1351-1357, https://doi.org/10.1002/ps.3727.

3. Bonny, S. Genetically Modified Herbicide-Tolerant Crops, Weeds, and Herbicides: Overview and Impact. Environmental Management 2016, 57, 31-48, https://doi.org/10.1007/s00267-015-0589-7.

4. Confortin, T.C.; Todero, I.; Soares, J.F.; Luft, L.; Brun, T.; Rabuske, J.E.; Nogueira, C.U.; Mazutti, M.A.; Zabot, G.L.; Tres, M.V. Extracts from Lupinus albescens: antioxidant power and antifungal activity in vitro against phytopathogenic fungi. Environmental Technology 2019, 40, 1668-1675, https://doi.org/10.1080/09593330.2018.1427800.

5. Todero, I.; Confortin, T.C.; Soares, J.F.; Brun, T.; Luft, L.; Rabuske, J.E.; Kuhn, R.C.; Tres, M.V.; Zabot, G.L.; Mazutti, M.A. Concentration of metabolites from Phoma sp. using microfiltration membrane for increasing bioherbicidal activity. Environmental Technology 2019, 40, 2364-2372, https://doi.org/10.1080/09593330.2018.1441330.

6. Balesteros, M.R.; de Sá, L.R.V.; Pereira, P.M.; da Silva, M.; de Oliveira, M.A.L.; Ferreira-Leitão, V.S. Monitoring of atrazine biodegradation by Pleurotus ostreatus INCQS 40310 through the simultaneous analysis of atrazine and its derivatives by HPLC. Biocatalysis and Biotransformation 2014, 32, 23-33, https://doi.org/10.3109/10242422.2013.870557.

7. Keerthi, P.; Singh, M.; Bishnoi, A. Role of Biological Control of Weeds and Bioherbicides. In: Advances in Agronomy. 1st ed.; Rawat, A.K.; Tripathi, U.K. Eds.; AkiNik Publications: New Delhi, India, Volume 4, 2019; pp. 61-79.

8. Reichert Júnior, F.W.; Scariot, M.A.; Forte, C.T.; Pandolfi, L.; Dil, J.M.; Weirich, S.; Carezia, C.; Mulinari, J.; Mazutti, M.A.; Fongaro, G.; Galon, L.; Treichel, H.; Mossi, A.J. New perspectives for weeds control using autochthonous fungi with selective bioherbicide potential. Heliyon 2019, 5, https://doi.org/10.1016/j.heliyon.2019.e01676.

9. Hassan, A.; Ahmad, W.; Israr, M. Evaluation of allelopathic effect of Carthamus Ozyacantha against wheat and maze seed germination. Lett Appl NanoBioScience 2020, 9, 814-818, https://doi.org/10.33263/LIANBS91.814818.

https://biointerfaceresearch.com/ 
10. Brun, T.; Rabuske, J.E.; Todero, I.; Almeida, T.C.; Junior, J.J.D.; Ariotti, G.; Confortin, T.; Arnemann, J.A.; Kuhn, R.C.; Guedes, J.V.C.; Mazutti, M.A. Production of bioherbicide by Phoma sp. in a stirred-tank bioreactor. 3 Biotech 2016, 6, 230-238, https://doi.org/10.1007/s13205-016-0557-9.

11. Brun, T.; Rabuske, J.E.; Todero, I.; Almeida, T.C.; Junior, J.J.D.; Ariotti, G.; Confortin, T.; Arnemann, J.A.; Kuhn, R.C.; Guedes, J.V.C.; Mazutti, M.A. Production of bioherbicide by Phoma sp. in a stirred-tank bioreactor. 3 Biotech 2016, 6, 1779-1783, https://doi.org/10.1021/jf304933z.

12. de Souza, A.R.C.; Baldoni, D.B.; Lima, J.; Porto, V.; Marcuz, C.; Ferraz, R.C.; Kuhn, R.C.; Jacques, R.J.S.; Guedes, J.V.C.; Mazutti, M.A. Bioherbicide production by Diaporthe sp. isolated from the Brazilian Pampa biome. Biocatalysis and Agricultural Biotechnology 2015, 4, 575-578, https://doi.org/10.1016/j.bcab.2015.09.005.

13. Souza, A.R.C.d.; Baldoni, D.B.; Lima, J.; Porto, V.; Marcuz, C.; Machado, C.; Ferraz, R.C.; Kuhn, R.C.; Jacques, R.J.S.; Guedes, J.V.C.; Mazutti, M.A. Selection, isolation, and identification of fungi for bioherbicide production. Brazilian Journal of Microbiology 2017, 48, 101-108, https://doi.org/10.1016/j.bjm.2016.09.004

14. Triolet, M.; Guillemin, J.P.; Andre, O.; Steinberg, C. Fungal-based bioherbicides for weed control: a myth or a reality? Weed Research 2020, 60, 60-77, https://doi.org/10.1111/wre.12389

15. Kaur, M.; Aggarwal, N.K. Comparative evaluation of phytotoxicity of Alternaria macrospora isolates, potential biocontrol agent against parthenium weed. Res. J. Bot. 2015, 10, 14-21, https://doi.org/10.3923/rjb.2015.14.21.

16. Kumar, M.; Madhupriya; Rao, G.P. Molecular characterization, vector identification and sources of phytoplasmas associated with brinjal little leaf disease in India. 3 Biotech 2017, 7, 1-11, https://doi.org/10.1007/s13205-017-0616-X.

17. Varejão, E.V.V.; Demuner, A.J.; Barbosa, L.C.A.; Barreto, R.W. The search for new natural herbicides Strategic approaches for discovering fungal phytotoxins. Crop Protection 2013, 48, 41-50, https://doi.org/10.1016/j.cropro.2013.02.008.

18. Iost, C.A.R.; Raetano, C.G. Dynamic surface tension and contact angle of water solutions with spray surfactants in artificial and natural surfaces. Eng Agr 2010, 30, 670-680, https://doi.org/10.1590/S010069162010000400011.

19. Mirgorodskaya, A.B.; Kushnazarova, R.A.; Lukashenko, S.S.; Nikitin, E.N.; Sinyashin, K.O.; Nesterova, L.M.; Zakharova, L.Y. Carbamate-bearing surfactants as effective adjuvants promoted the penetration of the herbicide into the plant. Colloids and Surfaces A: Physicochemical and Engineering Aspects 2020, 586, https://doi.org/10.1016/j.colsurfa.2019.124252.

20. De Almeida T. C.; Klaic, R.; Ariotti, G.; Sallet, D.; Spannemberg S. S.; Schmaltz, S.; Foletto E. L.; Kuhn R. C.; Hoffmann, R.; Mazutti, M.A. Production and formulation of a bioherbicide as environment-friendly and safer alternative for weed control. Biointerface Res. Appl. Chem., 2020, 10, 5938-5943, https://doi.org/10.33263/BRIAC104.938943

21. Bastos, B.d.O.; Deobald, G.A.; Brun, T.; Dal Prá, V.; Junges, E.; Kuhn, R.C.; Pinto, A.K.; Mazutti, M.A. Solid-state fermentation for production of a bioherbicide from Diaporthe $\mathrm{sp}$. and its formulation to enhance the efficacy. 3 Biotech 2017, 7, 135-143, https://doi.org/10.1007/s13205-017-0751-4.

22. Reveglia, P.; Cinelli, T.; Cimmino, A.; Masi, M.; Evidente, A. The main phytotoxic metabolite produced by a strain of Fusarium oxysporum inducing grapevine plant declining in Italy. Nat. Prod. Res. 2018, 32, 23982407, https://doi.org/10.1080/14786419.2017.1415897.

23. Pearson, K.A.; Taylor, A.F.S.; Fuchs, R.M.E.; Woodward, S. Characterisation and pathogenicity of Fusarium taxa isolated from ragwort (Jacobaea vulgaris) roots. Fungal Ecology 2016, 20, 186-192, https://doi.org/10.1016/j.funeco.2015.12.011.

24. Daniel, J.J.; Zabot, G.L.; Tres, M.V.; Harakava, R.; Kuhn, R.C.; Mazutti, M.A. Fusarium fujikuroi: A novel source of metabolites with herbicidal activity. Biocatalysis and Agricultural Biotechnology 2018, 14, 314320, https://doi.org/10.1016/j.bcab.2018.04.001.

25. Todero, I.; Confortin, T.C.; Luft, L.; Brun, T.; Ugalde, G.A.; de Almeida, T.C.; Arnemann, J.A.; Zabot, G.L.; Mazutti, M.A. Formulation of a bioherbicide with metabolites from Phoma sp. Scientia Horticulturae 2018, 241, 285-292, https://doi.org/10.1016/j.scienta.2018.07.009.

26. Frans, R.; Talbert, R.; Marx, D.; Crowley, H. Research methods in weed science. 3rd ed.; Champaign: Southern Weed Science Society, United States, 1986; pp. 29-46.

27. Hess, F.D.; Foy, C.L. Interaction of surfactants with plant cuticles. Weed Technol. 2000, 14, 807-813, https://doi.org/10.1614/0890-037X(2000)014[0807:IOSWPC]2.0.CO;2.

28. Pes, M.P.; Mazutti, M.A.; Almeida, T.C.; Curioletti, L.E.; Melo, A.A.; Guedes, J.V.C.; Kuhn, R.C. Bioherbicide based on Diaporthe sp. secondary metabolites in the control of three tough weeds. Afr. J. Agric. Res. 2016, 11, 4242-4249, https://doi.org/10.5897/AJAR2016.11639.

29. Aybeke, M. Fusarium infection causes genotoxic disorders and antioxidant-based damages in Orobanche spp. Microbiological Research 2017, 201, 46-51, https://doi.org/10.1016/j.micres.2017.05.001.

30. Li, S.; Shao, M.W.; Lu, Y.H.; Kong, L.C.; Jiang, D.H.; Zhang, Y.L. Phytotoxic and Antibacterial Metabolites from Fusarium proliferatum ZS07 Isolated from the Gut of Long-horned Grasshoppers. J Agric Food Chem 2014, 62, 8997-9001, https://doi.org/10.1021/jf502484n. 